\title{
FORMAC̣ÃO DE PROFESSORES E EDUCAC̣ÃO DE JOVENS E ADULTOS: O FORMAL E O REAL NAS LICENCIATURAS
}

\author{
Jaqueline Ventura* \\ Faculdade de Educação da Universidade Federal Fluminense (UFF) \\ Maria Inês Bomfim** \\ Faculdade de Educação da Universidade Federal Fluminense (UFF)
}

RESUMO: O presente estudo busca contribuir para o debate sobre o lugar que a Educação de Jovens e Adultos (EJA) ocupa na formação inicial de professores promovida nos cursos de licenciatura, destacando especificidades e lacunas observadas. Assinalando que o direito e a identidade própria da EJA estão garantidos desde a promulgação da atual Constituição Federal, retomam-se a legislação referente à formação de professores e, ainda, as Diretrizes Curriculares Nacionais de áreas selecionadas, nas quais se omitiu a especificidade da Educação de Jovens e Adultos. Por fim, avalia-se que o silêncio em relação à EJA nas licenciaturas se confunde com a situação dessa própria modalidade de ensino no Brasil. Alvo de metas modestas, políticas descontinuadas e fragmentadas, iniciativas focais e aligeiradas, a EJA traduz um projeto societário no qual a universalização da educação básica de qualidade para todos vem sendo assunto menor.

Palavras-chave: Educação de Jovens e Adultos. Formação Docente. Licenciaturas.

\footnotetext{
http://dx.doi.org/10.1590/0102-4698127011

* Doutora em Educação pela Universidade Federal Fluminense (UFF). Professora Adjunta da Faculdade de Educação da Universidade Federal Fluminense (UFF). Pesquisadora do Núcleo de Estudos Documentação e Dados em Trabalho e Educação (Neddate/UFF) e Laboratório de Investigação, Ensino e Extensão em Educação de Jovens e Adultos (LIEJA/UFRJ). E-mail: jaqventura@uol.com.br

* * Doutora em Educação pela Universidade Federal Fluminense (UFF). Professora Adjunta da Faculdade de Educação da Universidade Federal Fluminense (UFF). Pesquisadora do Núcleo de Estudos Documentação e Dados em Trabalho e Educação (Neddate/UFF) e do Grupo de PesquisaTrabalho e Formação Docente em Educação Profissional (UFF). E-mail: mariaines.uff@gmail.com
} 


\section{TEACHER TRAINING AND YOUTH AND ADULT EDUCATION: THE FORMALITY AND THE REALITY IN LICENTIATE DEGREE COURSES}

ABSTRACT: This study aims to contribute to the debate about the place that Youth and Adult Education (EJA) occupies in initial teacher training promoted by licentiate degree courses, highlighting gaps and specificities observed. Noting that the right and the identity of EJA is guaranteed since the promulgation of the Federal Constitution, it brings back to the table the legislation concerning teacher training and also the National Curriculum Guidelines of selected areas, in which EJA's specificity was omitted. The central hypothesis is that the silence regarding EJA in licentiate degree courses shows EJA's own situation in Brazil. Being a field of modest goals, discontinued policies and fragmented initiatives, EJA reflects a societal project in which the universalization of qualified basic education for all has been a minor issue.

Keywords: Youth and Adult Education. Teacher Training. Licenciate Degree Courses.

\section{INTRODUÇ̃̃̃O}

Neste artigo, situamos a Educação de Jovens e Adultos (EJA) numa perspectiva ampliada, abarcando tanto a alfabetização e a educação básica como as atividades voltadas à profissionalização. No Brasil, a origem e a trajetória dessa modalidade são marcadas por características articuladas. A vinculação da EJA aos subalternizados da sociedade, às frações mais empobrecidas da classe trabalhadora, excluídas até mesmo da estrutura dual do sistema escolar, explica muito da sua tradição: ações paralelas ao sistema regular de ensino, circunscritas à precariedade, à provisoriedade e à fragmentação. Tais características expressam a histórica omissão do Estado brasileiro no atendimento a uma grande parcela da população que permanece, ainda hoje, destituída de seu direito à educação básica.

Defendemos que a Educação de Jovens e Adultos não está fora ou acima da sociedade brasileira. Ela é parte constituída e constituinte do todo social, sendo que o processo histórico que nos trouxe até aqui foi capaz de configurar uma das sociedades mais desiguais do mundo. Assim, a especificidade da EJA requer analisá-la a partir daquilo que tem caracterizado a expansão capitalista no país, isto é, o desenvolvimento dependente, desigual e associado ao grande capital, instrumento de viabilização da inserção subalterna brasileira na divisão internacional do trabalho, destinando à grande maioria formação para o trabalho simples. 
Nessa perspectiva, a condição para que a formação humana seja considerada como estratégia de hegemonia do capital é que ela sofra um necessário reducionismo em forma de educação institucionalizada. À universalização da escolarização de jovens e adultos deverá, portanto, corresponder a restrição do acesso ao saber, definida pela divisão social do trabalho (CẾA, 2007). Em decorrência, a marca histórica das políticas públicas de Educação de Jovens e Adultos corresponde a uma educação pedagogicamente frágil, destinada, predominantemente, à correção de fluxo e à redução de indicadores de baixa escolaridade, e não à efetiva socialização das bases do conhecimento.

Os alunos da EJA, jovens com mais de 15 anos e adultos trabalhadores ou filhos deles, moradores do campo, das pequenas e das grandes cidades, das periferias, em situação de privação de liberdade etc., integram um conjunto extremamente diverso nos seus interesses e nas suas necessidades educacionais, embora esse conjunto expresse a desigualdade social existente no Brasil. Esses alunos encontram-se em desvantagem em relação ao acesso ao saber sistematizado, visto que a escolarização a eles destinada não tem assegurado a todos a apropriação dos instrumentos teórico-metodológicos disponíveis nos níveis superiores de ensino. Resta-lhes, na maioria das vezes, a aprendizagem do trabalho na prática do processo produtivo, que é, em geral, fragmentada e parcial (KUENZER,1997).

As políticas públicas federais referentes à educação de jovens e adultos e à educação profissional, incluindo o Plano Nacional de Qualificação dos Trabalhadores (PLANFOR), o Plano Nacional de Qualificação (PNQ), o Projeto Escola de Fábrica, o Programa Nacional de Inclusão de Jovens: Educação, Qualificação e Ação Comunitária (PROJOVEM), o Programa Nacional de Integração da Educação Profissional com a Educação Básica na Modalidade de Educação de Jovens e Adultos (PROEJA), o Exame Nacional para Certificação de Competências de Jovens e Adultos (ENCCEJA $)^{7}$ e, mais recentemente, o Programa Nacional de Acesso ao Ensino Técnico e Emprego (PRONATEC), já mostraram suas possibilidades e, especialmente, seus limites (RUMMERT et al, 2013; SHIROMA; LIMA FILHO, 2011).

O presente trabalho busca contribuir para o debate sobre o lugar ocupado pela Educação de Jovens e Adultos na formação inicial de professores promovida nos cursos de licenciatura, espaço privilegiado desta formação. Retomando a legislação referente à formação de professores para a educação básica, em nível superior, e as diretrizes curriculares de cursos superiores selecionados, assinalamos lacunas e desafios a serem enfrentados. 
Embora as conquistas no plano formal sejam fundamentais, resultado da luta da sociedade brasileira, vários estudos têm destacado o silêncio existente nos cursos de licenciatura em relação à EJA, em que pese a complexidade dessa modalidade. Diante disso, nossa hipótese central é que a frágil situação da formação docente inicial em EJA, em nível superior, se confunde com a da própria modalidade no Brasil. Alvo de metas modestas, políticas descontinuadas e fragmentadas, iniciativas focais e aligeiradas, a EJA traduz um projeto societário no qual a universalização da educação básica de qualidade para todos não é prioritária.

\section{EDUCAÇ̃̃O DE JOVENS E ADULTOS: DIREITOS E ESPECIFICIDADES ASSEGURADOS NO PLANO FORMAL}

No Brasil, parece existir um razoável consenso sobre as especificidades da Educação de Jovens e Adultos na legislação, além de uma vasta literatura produzida a respeito. O direito à EJA e a garantia de sua identidade como modalidade de características próprias estão definidos com clareza a partir da Constituição Federal de 1988. O inciso I do art. 208, alterado posteriormente pela Emenda Constitucional 59, de 2009, não deixa dúvidas a respeito. A Lei de Diretrizes e Bases da Educação (LDB) (Lei no 9.394/96), por sua vez, findou a terminologia e a concepção de ensino supletivo existentes na Lei 5.692/71. Com isso, a atual legislação tentou romper, ao menos no plano formal, com a visão da EJA como reposição de escolaridade, com currículo adaptado e redução do tempo e do conteúdo do ensino regular destinado a crianças e adolescentes. Na perspectiva da EJA, pelo contrário, os sistemas de ensino devem oferecer oportunidades educacionais apropriadas, considerando as características do alunado, seus interesses, suas condições de vida e de trabalho (Brasil, 1996).

O Parecer 11/2000, da Câmara de Educação Básica do Conselho Nacional de Educação (CNE), que define as Diretrizes Curriculares Nacionais para a EJA, caracteriza a modalidade como dívida social não reparada, reafirmando sua identidade própria: trata-se de uma categoria organizacional constante da estrutura da educação nacional, com finalidades e funções específicas (BRASIL, 2000). A LDB, o Parecer CNE 11/2000 e o novo Plano Nacional da Educação, coerentemente com a Constituição de 1988, esclarecem que os sistemas de ensino (municipal, no caso do Ensino Fundamental, e estadual, no caso do Ensino Médio) são os responsáveis pela construção de um modelo de educação escolar próprio, que não se equivale aos programas de aceleração da aprendizagem do ensino regular. 
Hoje, as ações relativas à Educação de Jovens e Adultos referem-se, além da possibilidade dos exames de certificação, a cursos e a variados programas dirigidos ao ingresso ou ao retorno à educação básica articulada, preferencialmente, à educação profissional (BRASIL, 2008). Sendo assim, do ponto de vista da atual legislação, a EJA tem como referência não apenas as suas próprias diretrizes curriculares, mas, também, as do Ensino Fundamental, do Ensino Médio e da educação profissional.

A oferta de cursos e de programas dirigidos à ampliação da escolaridade de jovens e de adultos requer conteúdos trabalhados de modo diferenciado de como ocorre no ensino regular, com métodos e tempos condizentes com o perfil do estudante jovem e adulto, ou seja, com a experiência que ele traz para o processo, como lembra Thompson (2002). Por isso mesmo, o tratamento didático dos conteúdos e das práticas não pode ignorar a especificidade da EJA, assim como o caráter multidisciplinar e interdisciplinar dos seus componentes curriculares (BRASIL, 2000).

Os cursos de Educação de Jovens e Adultos destinados aos maiores de 15 anos, no caso do Ensino Fundamental, e de 18 anos, no caso do Ensino Médio, são ofertados principalmente pelas redes públicas municipais e estaduais de ensino, enquanto os variados programas governamentais são geralmente impulsionados pelo Ministério da Educação (MEC) e desenvolvidos em parceria com entidades públicas ou privadas ${ }^{2}$.

Construir propostas político-pedagógicas de Educação de Jovens e Adultos que contribuam para superar o constante processo de privação do direito à educação básica de uma grande parcela da população brasileira não tem se constituído uma tarefa simples. Apesar do esforço de muitos professores e de algumas experiências inovadoras, não é raro encontrar propostas que preservam a lógica do ensino supletivo, marcadas por práticas aligeiradas, sob a justificativa de que os alunos precisam apenas de certificação que assegure a continuidade dos estudos ou o ingresso no mercado de trabalho. Além disso, observamos um silêncio escolar sobre o tema "trabalho", como adverte Ciavatta (2011), cuja natureza profunda e contraditória não é discutida também na Educação de Jovens e Adultos, visto que não há espaço na estrutura curricular para analisar o que são as relações de trabalho.

Elementos ideológicos das classes sociais e de grupos de interesses vários concorrem para esse obscurecimento generalizado sobre a escassez de empregos, a precarização dos vínculos de trabalho, a baixa remuneração, a regressão nos 
direitos trabalhistas, sob o slogan da "flexibilidade" necessária aos processos produtivos. Acrescente-se a isso o mito da empregabilidade pelo esforço individual, e do empreendedorismo no trabalho informal, esses, sim presentes - e positivamente referidos - em muitas proposições, em instrumentos legais, na publicidade e em diversos materiais didáticos voltados para a educação dos trabalhadores. (CIAVATTA, 2011, p. 34)

Pelo contrário, defendemos que a construção da identidade da Educação de Jovens e Adultos exigiria uma alteração significativa na organização curricular da escola pública, o que passa, entre outros desafios, pela compreensão por parte dos profissionais da educação (docentes e gestores) sobre o que é a EJA, sua constituição histórica, sua especificidade didático-metodológica, seu necessário compromisso com a classe trabalhadora, superando-se a "meiaeducação" (CIAVATTA, 2011) tradicionalmente oferecida.

Desse modo, será preciso reconhecer que a Educação de Jovens e Adultos se situa no âmbito das lutas por justiça social ao pretender uma formação para a produção da vida, e não apenas para a produção no mercado de trabalho. Sua principal função social será a construção de um processo educacional comprometido integralmente com o desenvolvimento pleno das potencialidades humanas, no qual os educandos se reconheçam como sujeitos histórico-sociais capazes de compreender e transformar as relações sociais.

\section{FORMAÇÃO DOCENTE EM NÍVEL SUPERIOR PARA A EDUCAÇÃO DE JOVENS E ADULTOS: O FORMAL E O REAL}

A análise da atual legislação revela que, no que toca à formação docente específica para a Educação de Jovens e Adultos e ao papel das licenciaturas, existem, também, indicações claras. A LDB afirma, em seu art. 61, a necessidade de formação de profissionais da educação de modo a atenderem aos objetivos dos diferentes níveis e modalidades de ensino e às características de cada fase do desenvolvimento do educando. $\mathrm{O}$ art. 62 esclarece que a formação de docentes para atuar na educação básica (o que inclui as suas modalidades) será realizada em nível superior, em curso de licenciatura, de graduação plena, em universidades e institutos superiores.

Nesse mesmo horizonte do reconhecimento de um espaço próprio de formação, o Parecer 11/2000 destaca que as licenciaturas e outras habilitações ligadas aos profissionais do ensino não podem deixar de considerar em seus cursos a realidade da Educação de Jovens e Adultos (BRASIL, 2000). O parecer sublinha, ainda, que 
a complexidade diferencial dessa modalidade de ensino não se realiza satisfatoriamente com um professor motivado apenas "pela boa vontade ou por um voluntariado idealista", uma vez que não se pode "infantilizar" a EJA no que diz respeito a métodos, conteúdos e processos (BRASIL, 2000). Tal complexidade requer considerar os múltiplos saberes que os alunos dessa modalidade raramente externam, muitas vezes desvalorizados pela escola.

Preocupações semelhantes foram incluídas no Parecer 9/2001, do Conselho Nacional de Educação, que definiu as Diretrizes Curriculares Nacionais para a Formação de Professores da Educação Básica (BRASIL, 2002), em nível superior, em curso de licenciatura, de graduação plena, com repercussões para as disciplinas teóricas e práticas de todos os cursos que formam professores, e não apenas para a licenciatura em Pedagogia. O Parecer 9/2001 considera que, no Brasil, um curso de formação de professores não pode deixar de lado a questão da Educação de Jovens e Adultos, que ainda é uma necessidade social expressiva.

Inúmeras experiências apontam a necessidade de pensar a especificidade desses
alunos e de superar a prática de trabalhar com eles da mesma forma que se
trabalha com os alunos do ensino fundamental ou médio regular. Apesar de
se tratar das mesmas etapas de escolaridade (ensino fundamental e médio),
os jovens e adultos, por estarem em outros estágios de vida, têm experiências,
expectativas, condições sociais e psicológicas que os distanciam do mundo
infantil e adolescente, o que faz com que os professores que se dedicam a
esse trabalho devam ser capazes de desenvolver metodologias apropriadas,
conferindo significado aos currículos e às práticas de ensino. A construção de
situações didáticas eficazes e significativas requer compreensão desse universo,
das causas e dos contextos sociais e institucionais que configuram a situação de
aprendizagem dos seus alunos. (BRASIL, 2002, p. 26)

Entretanto, os preceitos dessa legislação não foram incorporados de forma clara nas Diretrizes Curriculares Nacionais de cursos superiores como, por exemplo, História, Letras e Ciências Biológicas, nas quais as especificidades da formação voltada para a Educação de Jovens e Adultos, como modalidade, não são explícitas:

O graduado deverá estar capacitado ao exercício do trabalho de historiador [...] específic[o] para licenciatura: a) domínio dos conteúdos básicos que são objeto de ensino - aprendizagem no ensino fundamental e médio; b) domínio dos métodos e técnicas pedagógicos que permitem a transmissão do conhecimento para os diferentes níveis de ensino. (BRASIL, 2001a, p. 8)

De forma integrada aos conteúdos caracterizadores básicos do curso de Letras, devem estar os conteúdos caracterizadores de formação profissional em Letras. [...] No caso das licenciaturas deverão ser incluídos os conteúdos definidos para a educação básica, as didáticas próprias de cada conteúdo e as pesquisas que as embasam. (BRASIL, 2001a, p. 31) 
A modalidade licenciatura deverá contemplar, além dos conteúdos próprios das Ciências Biológicas, conteúdos nas áreas de Química, Física e da Saúde, para atender ao ensino fundamental e médio. A formação pedagógica, além de suas especificidades, deverá contemplar uma visão geral da educação e dos processos formativos dos educandos. Deverá também enfatizar a instrumentação para o ensino de Ciências no nível fundamental e para o ensino da Biologia, no nível médio. (BRASIL, 2001b, p. 6)

As lacunas em relação à Educação de Jovens e Adultos nas licenciaturas, de forma geral, vêm sendo apontadas em inúmeros estudos. Análises realizadas por Di Pierro (2006), Gatti e Barreto (2009), por exemplo, assinalam tanto o lugar secundário da preparação para a docência como o silêncio em relação ao trabalho específico em EJA, ausente na maioria das experiências de formação inicial em cursos de licenciatura que habilitam o profissional a exercer a docência numa dada área do conhecimento, nos níveis e nas modalidades da educação básica. A questão, portanto, coloca-se em torno dos limites dessa formação, isto é, da não explicitação do seu compromisso com a educação destinada aos alunos jovens e adultos que integram as frações mais empobrecidas da classe trabalhadora.

Tal ausência foi enfaticamente denunciada no I Seminário Nacional de Formação de Educadores de Jovens e Adultos, promovido pelos Fóruns de EJA, que representam diferentes segmentos da sociedade civil, e pelo Ministério da Educação ${ }^{3}$, em 2006, quando algumas soluções, ainda que parciais, foram discutidas.

Num esforço de instaurar essa discussão no âmbito dos cursos de licenciatura, uma alternativa experimentada em algumas universidades tem sido a de abrir aos demais licenciandos a oportunidade de cursar, como eletivas, as disciplinas específicas das habilitações em EJA dos cursos de Pedagogia que a possuem ou a de conceder-lhes a oportunidade de participar de projetos de extensão universitária no campo da EJA. (DI PIERRO, 2006, p. 285)

Outros estudos reforçam a existência de tais lacunas (SOARES, 2008; PORCARO, 2011) com base na observação do desconforto e da insegurança dos professores que atuam na Educação de Jovens e Adultos diante da desafiadora realidade que se expressa nos espaços-tempos escolares da modalidade. Nesse quadro, é necessário reconhecer que, salvo algumas importantes exceções identificadas em propostas curriculares inovadoras e, especialmente, em atividades de extensão universitária, a modalidade não tem se constituído tema prioritário na universidade, nem no que diz respeito à formação, nem no que concerne à produção científica. No caso da produção científica, de acordo com os levantamentos realizados por Machado 
(2002), Pereira (2006), Carvalho (2009) e Di Pierro (2011), é ainda incipiente o conhecimento acumulado sobre a formação inicial de professores para a Educação de Jovens e Adultos.

Arroyo (2006), discutindo essas ausências, defende que os futuros professores de EJA precisariam conhecer as especificidades do que é ser jovem, do que é ser adulto. Tudo deveria girar em torno disso, avalia. Entretanto, "não é qualquer jovem e qualquer adulto. São jovens e adultos com rosto, com histórias, com cor, com trajetórias sócio-étnico-raciais, do campo, da periferia" (ARROYO, 2006, p. 22). Esse conhecimento requer pesquisa e produção teórica dos próprios educadores da EJA, sendo a formação inicial um dos espaços para essa construção. Na mesma direção, Ribeiro (1999) propõe o amadurecimento de uma psicologia de adultos, visando superar a concepção de que o desenvolvimento é algo que ocorre apenas durante a infância e a adolescência, enquanto Pereira (1999) sustenta que a formação deve contemplar vivências na escola básica não só com crianças e adolescentes, mas com jovens e adultos.

Observamos, assim, que na universidade as lacunas na formação inicial para a EJA estão também imbricadas com as lacunas na produção científica sobre o tema, em que pesem algumas experiências de grande relevância. Um estudo preliminar a partir do banco de teses da Coordenação de Aperfeiçoamento de Pessoal de Nível Superior (CAPES) e do Centro de Referência em Educação de Jovens e Adultos (CEREJA), no período de 2000 a 2006, revelou que, entre as 518 dissertações defendidas sobre EJA, apenas 44 tinham como objeto a formação docente. Das 77 teses de doutorado, somente cinco tratavam do tema ${ }^{4}$. Como expressão desse quadro, André (2002) e Brzezinski (2006), ao avaliarem a produção específica do Grupo de Trabalho (GT) Formação de Professores, da Associação Nacional de Pesquisa e PósGraduação em Educação (ANPED), reafirmaram a baixa produção sobre a formação docente em Educação de Jovens e Adultos.

Nossa experiência com a Educação de Jovens e Adultos em uma universidade federal do Rio de Janeiro traz outras contribuições a essa discussão. A Faculdade de Educação em que atuamos forma professores no curso de Pedagogia para a educação infantil e as séries iniciais do Ensino Fundamental e participa da formação dos alunos das demais licenciaturas mediante a oferta de disciplinas teórico-práticas que compõem o eixo pedagógico. "Educação de Jovens e Adultos" é uma das disciplinas obrigatórias no currículo do curso de Pedagogia há vários anos, tal como em outras universidades, embora não exista nenhuma indicação dessa obrigatoriedade para as demais licenciaturas. 
A proposta pedagógica de formação de educadores de jovens e adultos nas iniciativas desenvolvidas pelas autoras do presente estudo nos cursos de graduação, especialização e nas atividades de extensão está estruturada a partir de bases teórico-metodológicas que apresentam a "concepção de trabalho como produção da existência e a história das lutas de múltiplos agentes sociais pelo direito à educação" (RUMMERT, 2006, p. 138) . Nessa direção, explicitando a importância da educação como espaço de luta, a disciplina na graduação em Pedagogia foi organizada em torno das seguintes finalidades: a) compreensão da EJA na perspectiva histórica, conhecendo seus condicionantes sociais, políticos e econômicos; b) reflexão sobre as especificidades e as prioridades da EJA no Brasil, hoje, como expressões desses condicionantes históricos; c) conhecimento dos principais fundamentos teórico-metodológicos da EJA; d) reflexão sobre a formação do educador frente à especificidade da EJA; e) análise das principais demandas e das ações atuais do Estado, do capital e do trabalho no âmbito da EJA (RUMMERT, 2006, p. 137).

A disciplina, entretanto, é optativa para as demais licenciaturas e, nessa condição, em virtude da escassez de docentes e do crescimento de matrículas nas licenciaturas, tem sido oferecida não em função da sua real necessidade, mas da disponibilidade de professores para tal. Além disso, cabe assinalar que o modelo vigente ainda não contempla, nas demais disciplinas teóricas e práticas das licenciaturas, nem mesmo na Pedagogia, uma reflexão mais detida sobre o ensino e a aprendizagem de jovens e adultos. As especificidades, de maneira geral, não são aprofundadas, já que as ênfases permanecem sendo a educação infantil e as séries iniciais do Ensino Fundamental, no caso da licenciatura em Pedagogia, bem como as séries finais do Ensino Fundamental e o Ensino Médio regular, no caso das demais licenciaturas. ${ }^{6}$

O contato com os alunos do curso de Pedagogia e com os das demais licenciaturas tem nos mostrado que os estudantes desconhecem a problemática da Educação de Jovens e Adultos, bem como o seu sentido numa sociedade que, historicamente, vem negando o direito à escola de qualidade para todos. Encontramos certa perplexidade em relação às necessidades desses sujeitos, em geral secundarizados na sua formação. Apesar disso, consideramos que os resultados têm sido positivos para que os futuros professores compreendam não só as especificidades da EJA, mas as suas potencialidades.

De toda forma, o esforço realizado na instituição, embora louvável, fica aquém do desafio de formar professores para atuarem na EJA presencial do Estado do Rio de Janeiro, que, em 2012, contava com mais de 220 mil alunos matriculados em todas as redes, sendo 147.776 no Ensino Fundamental e 73.693 no Ensino Médio (BRASIL, 2013). 
LICENCIATURASE EDUCAC̣ÃO DE JOVENSE ADULTOS: BREVES CONSIDERAC̣ÕES FINAIS

A Educação de Jovens e Adultos ainda ocupa lugar pouco destacado não apenas nas propostas curriculares de formação inicial, mas, também, na produção científica acadêmica. Não são poucos os estudos que analisam esse quadro nos últimos dez anos. Interessa, portanto, avançar no debate sobre as possíveis razões dessa realidade.

Educação, como sabemos, é prática social. Campo de disputas hegemônicas no interior das relações de produção, a EJA, sob o modo de produção capitalista, articula-se aos processos de reprodução mais amplos, contribuindo para a construção de uma sociabilidade adequada ao sistema, visto que a lógica de preservação do próprio capital implica distribuição desigual do saber entre as classes. Os indivíduos são considerados iguais em relação às leis, ao direito à vida, à liberdade, à propriedade e também à educação, embora não sejam material e socialmente iguais, particularmente naquilo que mais contribui na fixação dos limites da sua ação, isto é, na sua posição dentro da estrutura econômica da sociedade.

No essencial, a liberal-democracia, vestimenta jurídica e política do capitalismo, precisa respeitar a livre determinação dos indivíduos na base de seus interesses pessoais e deixar à concorrência natural espontânea entre eles o ajustamento e a harmonização de seus interesses respectivos (PRADO JÚNIOR, 1985). Os que sobram integram as frações mais empobrecidas da classe trabalhadora, restando-lhes a Educação de Jovens e Adultos, oferecida frequentemente em condições precárias, por professores muitas vezes bem-intencionados, mas sem uma sólida formação.

No campo pedagógico, predominam formulações que desprezam as relações entre formação humana, conhecimento e classe social e deixam de considerar que os indivíduos a serem educados na EJA são formados histórica e socialmente. Com frequência, o mercado de trabalho é mistificado, os embates são suavizados, e a educação escolar, definida como a solução para todos os males. De tal superficialidade, decorrem tanto a naturalização das desigualdades sociais e do acesso diferenciado ao direito à educação como a responsabilização dos indivíduos pelo seu sucesso ou fracasso, visões funcionais ao sistema social e produtivo. Tais visões, vale dizer, não são casuais e decorrem de um processo histórico cuja apreensão é indispensável para se discutir possibilidades concretas de atuação na Educação de Jovens e Adultos. 
Por tudo isso, é essencial assegurar nessa modalidade a leitura, a escrita, a biologia, a história, a matemática, a geografia, a física etc. como instrumentos indispensáveis à compreensão da realidade em que vivemos e à preparação para o trabalho, o que faz da seleção curricular uma questão ético-política. Pensar a escola de Educação de Jovens e Adultos, devido às suas especificidades, vai exigir dos professores de todas as áreas considerar a prática social como ponto de partida, o que requer um aprofundamento teórico-metodológico sobre essa modalidade, ainda ausente em boa parte dos cursos de licenciatura.

Nos limites dos objetivos da discussão aqui realizada, mas compreendendo que o debate sobre a formação inicial em EJA, em nível superior, não se dá no abstrato, cabe também lembrar a origem histórica das licenciaturas brasileiras, nos anos de 1930. A proposta predominante era a que dedicava de forma desarticulada três anos às disciplinas de conteúdo específico e um ano às disciplinas de natureza pedagógica. De lá para cá, as sucessivas mudanças promovidas não conseguiram, ainda, estabelecer um padrão consistente de preparação para fazer face aos problemas enfrentados pela educação escolar no nosso país, o que inclui a EJA (SAVIANI, 2009).

Especificamente em relação à formação inicial de professores, Soares (2006), estudando tendências no plano das políticas e da literatura especializada sobre a formação de professores no período 2000-2007, observa a existência de três eixos articulados e incompatíveis com as necessidades aqui indicadas no que concerne à Educação de Jovens e Adultos: o empobrecimento da noção de conhecimento, a excessiva valorização da epistemologia da prática e o enaltecimento das competências. Além disso, as soluções propostas pelas políticas de formação continuada, em nível nacional, são ainda parciais. A formação, predominantemente com base em cardápios de ofertas padronizadas e desenvolvida expressivamente à distância, reitera soluções restritas já adotadas anteriormente. ${ }^{7}$

Superar esse quadro não tem sido tarefa simples, em que pesem as ricas discussões que há décadas são realizadas em torno da formação inicial. Um dos desafios, certamente, é repensar as formas clássicas, que ignoram tanto a prática social na qual os alunos da EJA se inserem como a experiência do trabalho docente na modalidade. Por isso mesmo, as licenciaturas permanecem entre as áreas mais críticas do campo da educação, devendo ser a Educação de Jovens e Adultos uma de suas questões prioritárias.

É nessa materialidade que o lugar da EJA na formação inicial precisaria ser discutido, tendo em mente o que Gatti e Barreto (2009) 
sublinham: existe uma ordem hierárquica na academia universitária, sendo que a dedicação ao ensino e à formação de professores supõe, frequentemente, perda de prestígio acadêmico. A esse respeito, compreendemos que uma proposta curricular de formação docente é expressão de relações de hegemonia num dado momento histórico, o que nos ajuda a compreender as lacunas em relação à EJA nas licenciaturas, apesar da necessidade de uma sólida formação para o trabalho nesta modalidade, reconhecida até mesmo na legislação em vigor. Assim, cabe lembrar que:

a educação formalizada é um dos processos pelos quais a sociedade se configura, mas não é, como pensa a pedagogia ingênua, o único que a configura. Todos os processos configuradores da sociedade estão em estreita relação recíproca e se influenciam mutuamente [...]. A pergunta fundamental, da qual deve partir toda a discussão da formação do professor, é esta: "quem educa o educador"? [...] A resposta correta é a que mostra o papel da sociedade como educadora do educador. (PINTO, 1986, p. 108-109)

Entretanto, não é possível desprezar o fato de que o Estado, historicamente a serviço dos interesses privados, conhece bem as possibilidades do processo formativo que, comprometido com o professor e a realidade concreta brasileira, busca as raízes das questões a serem superadas. Paradoxalmente, parte da produção atual sobre a Educação de Jovens e Adultos pauta-se na potencialidade da modalidade na formação para uma cidadania abstrata, capaz de atenuar os antagonismos de classe da sociedade capitalista, de superar a tradição histórica da educação compensatória.

Esse modo de pensar a Educação de Jovens e Adultos, de acordo com a nossa análise, concorre para a produção de ideias que "evadem a compreensão de como a realidade se produz em todas as suas dimensões (econômica, política, cultural, educacional etc.)" (FRIGOT'TO, 2011, p. 106). Além disso, secundariza o fato de que o sistema capital não promoverá a educação que efetivamente interessa aos trabalhadores, de forma a concorrer voluntariamente para a corrosão de suas próprias bases (RUMMERT, 2006). Como sublinha Mészáros (2004), esperar da sociedade mercantil a promulgação ativa ou mesmo a mera tolerância de um mandato às suas instituições de educação formal que as convidasse a abraçar a grande tarefa histórica do nosso tempo, ou seja, a tarefa de romper com a lógica do capital no interesse da sobrevivência humana, seria um milagre monumental.

Desse modo, o lugar pouco significativo da EJA nas propostas curriculares das licenciaturas é, na nossa avaliação, uma das faces de um mesmo problema que as conquistas formais na legislação, por si 
só, não poderiam superar. Apesar desse limite, é preciso lembrar que os seres humanos têm a capacidade de intervir na realidade não só para mantê-la tal como ela se apresenta, mas para rejeitá-la ou transformála. Sua capacidade de intervenção crítica, porém, dependerá do grau de consciência que eles têm dessa mesma realidade. Em outras palavras, para agir criticamente será preciso saber para que agir, com que meios se pode agir, o que conservar e o que superar, deixando claro o potencial da formação inicial, promovida em nível superior, para o trabalho na Educação de Jovens e Adultos.

Falamos, portanto, de uma formação inicial de professores para a ação autônoma e criativa nas condições sociais em que a EJA se inscreve. Trata-se, assim, como defende Rummert (2006), de uma concepção de formação que não se pretende prescritiva nem formadora de profissionais marcados pela heteronomia. Pelo contrário, buscase a "construção da autonomia, socialmente comprometida, visando à superação das atuais condições de existência e às transformações estruturais da sociedade" (RUMMERT, 2006, p. 135).

Ao encerrar estas breves considerações, sempre abertas ao debate, parece oportuno ressaltar uma das importantes contribuições de Thompson (2002) à discussão aqui empreendida: precisamos lembrar que a universidade se engaja na Educação de Jovens e Adultos não apenas para ensinar, mas para aprender. Sendo assim, retomar a discussão sobre as possibilidades da formação inicial em Educação de Jovens e Adultos é, ainda, prioridade.

\section{REFERÊNCIAS}

ARROYO, M. Formar educadores de jovens e adultos. In: SOARES, L. (Org.). Formação de educadores de jovens e adultos. Belo Horizonte: Autêntica/MEC/ UNESCO, 2006. p. 17-32.

ANDRÉ, M. E. D. A. Formação de professores no Brasil (1990-1998). Série Estado do Conbecimento, n. 6, Brasília: MEC/Inep/Comped, 2002. p. 171-174.

BRASIL. Lei 11.741, de 16 de julho de 2008. Diário Oficial da União, Brasilia, 17 ago. 2008, Seção 1, p.5 BRASIL. CNE/CEB. Parecer n ${ }^{\circ} 11 / 2000$. Diretrizes Curriculares Nacionais para a Educação de Jovens e Adultos. Relator: Carlos Roberto Jamil Cury, aprovado em 10/05/2000. Diário Oficial da União, MEC/CNE/CEB, Brasília, 9 jun. 2000, Seção 1e, p. 15.

. CNE/CP. Parecer no 09/2001, de 8 de maio de 2001. Diretrizes Curriculares Nacionais para a Formação de Professores da Educação Básica, em nível superior, curso de licenciatura, de graduação plena. Diário Oficial da União, MEC/CNE, Brasília, 18 jan. 2002, Seção 1, p. 31.

CNE/CES. Parecer no 492/2001, de 3 de abril de 2001. Diretrizes Curriculares Nacionais dos cursos de Filosofia, História, Geografia, Serviço Social, Comunicação Social, Ciências Sociais, Letras, Biblioteconomia, Arquivologia e Museologia. Diário Oficial da União, MEC/CNE, Brasília, 9 jul. 2001a Seção 1 e, p. 50. 
CNE/CES. Parecer 1.301/2001, de 6 de novembro de 2001. Diretrizes Curriculares Nacionais para os Cursos de Graduação em Ciências Biológicas. Conselho nacional de Educação, Ministério da Educação, Poder Executivo, Brasília, DF, 2001c. Diário Oficial da União, MEC/CNE/CES, Brasília, 7 dez. 2001b Seção 1e, p. 25.

MEC/INEP. Resultados Finais do Censo Escolar 2012: Brasília, 2013. Disponível em: <http://portal.inep.gov.br/basica-censo-escolar-matricula>. Acesso em: mai. 2013.

BRZEZINSKI, I. (Coord.). Formação de profissionais da educação (1997-2002). Brasília, DF: MEC/INEP, 2006. (Série Estado do Conhecimento, v. 10).

CARVALHO, R. V. O estado da arte das pesquisas em Educação de Jovens e Adultos na CAPES: período de 1987-2006. Cadernos de Pesquisa Pensamento Educacional [online], Curitiba, v. 4, n. 8, p. 117-130, jul./dez. 2009. Disponível em: < http://www.utp.br/revistaseletronicas. asp>. Acesso em: mar. 2012.

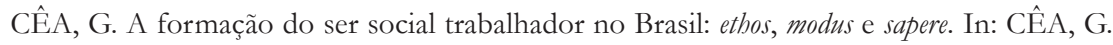
(Org). O estado da arte da formação do trabalhador no Brasil: pressupostos e ações governamentais dos anos 1990. Cascavel: EDUNIOESTE, 2007.

CIAVATTA, M. A reconstrução histórica de trabalho e educação e a questão do currículo na formação integrada. In: CIAVATTA, M.; TIRIBA, L. Trabalho e Educação de Jovens e Adultos. Brasília: Liber Livro e Editora UFF, 2011.

DI PIERRO, M. C. Contribuições do I Seminário Nacional de Formação de Educadores de Jovens e Adultos. In: SOARES, L. (Org.). Formação de Educadores de Jovens e Adultos. Belo Horizonte: Autêntica/MEC/ Unesco, 2006. p. 281-291.

Balanço e perspectivas da pesquisa sobre formação de educadores/as de jovens e adultos. In: OLIVEIRA, E. F. et al. (Orgs.). Formação de Educadores de Educação de Jovens e Adultos. Porto Alegre: Deriva, 2011.

FÁVERO, O. et al. Formação de profissionais para a educação de jovens e adultos trabalhadores. Educação em Revista, Belo Horizonte, n. 30, p. 39-49, dez. 1999.

FERNANDES, F. A formação política e o trabalho do professor. In: CATANI, D. B.; MIRANDA, H. T. de; MENEZES, L. C.; FISCHMANN, R. (Orgs.). Universidade, Escola e Formação de Professores. São Paulo: Editora Brasiliense, 1986.

FRIGOTTO, G. Juventude, trabalho e educação: o presente e o futuro interditados ou em suspenso. In: TIRIBA, L; CIAVATTA, M. (Org.). Trabalho e Educação de Jovens e Adultos. Brasília: LIBER Livro e Editora /UFF, 2011.

GATTI, B.; BARRETO, E. (Org.). Professores do Brasil: impasses e desafios. Brasília: Unesco, 2009. KUNZER, A. A relação entre educação e trabalho: pressupostos teóricos. In: Ensino de $2^{\circ}$ Grau: O trabalho como princípio educativo. SP: Cortez, 1997.

MACHADO, M. M. O professor. In: HADDAD, S. (Coord.). Educação de jovens e adultos no Brasil (1986-1998). Brasília, MEC/Inep/Comped, 2002. p. 25-47. (Estado do Conhecimento, 8).

MÉSZÁROS, I. A educação para além do capital. Intervenção na abertura no Fórum Mundial de Educação, Porto Alegre, Brasil, 28 jul. 2004. Disponível em: < http:/ / resistir.info/meszaros / meszaros_educacao.html>Acesso em: mai. 2015.

PEREIRA, J. D. As licenciaturas e as novas políticas educacionais para a formação docente. Educação \& Sociedade, Campinas-SP, v. especial, n. 68, p. 109-125, dez. 1999.

. Estudos e pesquisas sobre formação de educadores de jovens e adultos: análise dos trabalhos e pôsteres aprovados na ANPEd (2000-2005). In: SOARES, L. (Org.). Formação de Educadores de Jovens e Adultos. Belo Horizonte: Autêntica/MEC/ Unesco, 2006. 
PINTO, A. V. Sete lições sobre educação de adultos. São Paulo: Cortez: Editores Associados, 1986. PRADO JÚNIOR, C. O que é liberdade. São Paulo: Editora Brasiliense, 1985.

PORCARO, R. C. Caminhos e desafios da formação de educadores de jovens e adultos. 186f. Tese (Doutorado em Educação) - Faculdade de Educação da Universidade Federal de Minas Gerais. Belo Horizonte: UFMG, 2011.

RIBEIRO, V. M. A formação de educadores e a constituição da educação de jovens e adultos como campo pedagógico. Educação \& Sociedade, Campinas-SP, v. 20, n. 69, p. 184-201, 1999.

RUMMERT, S. M. Formação continuada de educadores de jovens e adultos: desafios e perspectivas. In: SOARES, L. (Org.). Formação de educadores de jovens e adultos. Belo Horizonte: Autêntica/MEC/ Unesco, 2006. p. 123-140.

RUMMERT, S. M. et al. Educação e formação humana no cenário de integração subalterna no capital-imperialismo. Revista Brasileira de Educação, 2013. (No prelo).

SAVIANI, D. Formação de professores: aspectos históricos e teóricos do problema no contexto brasileiro.Revista Brasileira de Educação.[online], Rio de Janeiro, 2009, vol.14, n.40, p. 143-155. Disponível em: <http://dx.doi.org/10.1590/S1413-24782009000100012>. Acesso em: mai. 2013.

SOARES, K. C. D. Trabalho e formação docentes: tendências no plano das políticas e da literatura especializada. In: REUNIÃO ANUAL DA ASSOCIAÇÃO NACIONAL DE PÓSGRADUAÇÃO E PESQUISA EM EDUCAÇÃO (ANPED), 29., 2006, Caxambu. Anais... Caxambu, 2006. Disponível em: <http://www.anped.org.br>. Acesso em: mai. 2013.

SOARES, L. Avanços e desafios na formação do educador de jovens e adultos. O educador de jovens e adultos e sua formação. Educacão em Revista, Belo Horizonte, n. 47, p. 83-100, jun. 2008.

SHIROMA, E.; LEITE FILHO, D. Educação e trabalho docente na educação profissional e tecnológica e no PROEJA. Educação \& Sociedade, Campinas-SP, v. 32, n. 116, p. 725-743, jul./set. 2011.

THOMPSON, E. P. Educação e Experiência. In: THOMPSON, Edward P. Os românticos. A Inglaterra na era revolucionária. Rio de Janeiro: Civilização Brasileira, 2002.

\section{NOTAS}

${ }^{1} \mathrm{O}$ Exame Nacional de Certificação de Competências (ENCCEJA) é promovido pelo Instituto Nacional de Estudos e Pesquisas Educacionais Anísio Teixeira e o Ministério da Educação (INEP/MEC), em articulação com os Estados.

${ }^{2}$ Grande parte desses programas caracteriza-se pela instabilidade, tanto por sua incerta duração, quanto por seus distintos padrões de organização, implicados com pouca precisão sobre seus vínculos institucionais reais. Outro aspecto que merece destaque é que muitos programas apresentam um confuso delineamento formativo, compondo um mosaico com durações e conteúdos diversos (RUMMERT et al., 2013).

${ }^{3}$ As publicações decorrentes dos três encontros nacionais ocorridos em 2006, 2008 e 2010 estão disponíveis em: <http://forumeja.org.br/iiisnfbrasil>. Acesso em: 29 mai. 2015.

4 Levantamento preliminar realizado pelo Grupo de Estudos: Políticas de Educação de Jovens e Adultos Trabalhadores sobre a produção acadêmica relativa à Educação de Jovens e Adultos. Disponível em: <http://www.uff.br/ejatrabalhadores/>. Acesso em: 15 jan. 2013.

${ }^{5}$ A proposta, desenvolvida desde 1998 no âmbito da instituição para formação inicial e continuada em EJA, encontra-se sistematizada em Fávero et al (1999) e em Rummert (2006). 
${ }^{6}$ Cabe destacar experiências conjuntas recentes com professores de prática em História no contexto do Programas Institucional de Bolsa de Iniciação à Docência (PIBID), c ujas perspectivas são promissoras.

${ }^{7}$ Ver a política de formação docente do governo federal estabelecida, em janeiro de 2009, pelo Decreto $n^{\circ} 6.755$ e a oferta de formação continuada na Plataforma Paulo Freire, do Ministério da Educação.

Recebido: 13/12/2013

Aprovado: 28/02/2015

Contato:

Universidade Federal Fluminense (UFF)

Rua Professor Waldemar Freitas Reis, s/ $\mathrm{n}^{\circ}$, Bloco D, $4^{\circ}$ andar - Gragoatá/São Domingos

Niterói |RJ |Brasil

CEP 24.210-201 
